This is a self-archived version of an original article. This version may differ from the original in pagination and typographic details.

Author(s): Mänttäri-van der Kuip, Maija

Title: Conceptualising Work-Related Moral Suffering : Exploring and Refining the Concept of Moral Distress in the Context of Social Work

Year: 2020

Version: Accepted version (Final draft)

Copyright: (c) The Author(s) 2019

Rights: In Copyright

Rights url: http://rightsstatements.org/page//nC/1.0/?language=en

Please cite the original version:

Mänttäri-van der Kuip, M. (2020). Conceptualising Work-Related Moral Suffering : Exploring and Refining the Concept of Moral Distress in the Context of Social Work. British Journal of Social Work, 50(3), 741-757. https://doi.org/10.1093/bjsw/bcz034 


\title{
Conceptualising Work-Related Moral Suffering - Exploring and Refining the Concept of Moral Distress in the Context of Social Work
}

\begin{abstract}
In the nursing literature, work-related suffering due to restricted moral agency is commonly considered under the concept of moral distress. This concept has resonated strongly among nursing scholars since the 1980s and has recently gained ground among social work scholars as well. However, the research on moral distress suffers from inadequate conceptual clarity; this has led to multiple and disparate ways of empirically studying the phenomenon. This article examines the conceptualisations of moral distress applied in the nursing and social work literature and identifies and discusses the challenges and potential problems related to them. The article sheds light on the complex, dynamic and relative nature of the phenomenon, which has not been sufficiently acknowledged in the existing empirical literature. Despite its complexities and defects, as highlighted in this article, the concept of moral distress can serve as an important tool for understanding and analysing experiences of moral suffering in frontline social work. However, defining this experience in all its complexity and devising a valid instrument to measure it remain a major challenge.
\end{abstract}

Key words: moral distress, well-being, ethics, social work 


\section{Introduction}

The commitment and capability of social workers to function according to the ethical principles of social work (IFSW, 2018) are crucial to the quality of their practice (Ulrich et al. 2007). However, in the current welfare context, shaped by controversial ideological transformations, restructuring, and the implementation of diverse austerity measures (see Baines and van den Broek, 2017; Garret and Bertotti, 2017), it is increasingly challenging for social workers to realise their professional aspirations (e.g. Welbourne, 2011; Ferguson and Lavalette, 2013; Fronek and Chester, 2016; Shdaimah and McGarry, 2018). Numerous studies have demonstrated that social workers are struggling in their efforts to meet the needs of service users and comply with their professional moral code (e.g. Conneely and Garrett, 2015; Grootegoed and Smith, 2018). In these challenging circumstances, they are at high risk for work-related suffering, such as stress, burnout (e.g. Kim et al., 2011; Ravalier 2018; Baugerud et al., 2018) and anguish related, in particular, to their compromised moral agency (e.g. Ulrich et al., 2007; Fenton 2014; Mänttäri-van der Kuip, 2016).

For social workers, the inability to implement the ethical principles that are expected to guide their practice can be highly stressful. In the nursing literature, such work-related suffering due to restricted moral agency is commonly addressed using the concept of moral distress (see McCarthy and Gastmans, 2015). This concept, first introduced by the American bioethicist Andrew Jameton during the early 1980s, has resonated strongly among nursing scholars (see Jameton, 1984). Study of the phenomenon has become increasingly popular over the past thirty years in the field of nursing and bioethics and has also gained a foothold among social work 
scholars (see Weinberg 2009; Sunderland et al., 2010; Mänttäri-van der Kuip, 2016; Lynch and Forde, 2016; Lev and Ayalon, 2016; 2018; Fantus et al., 2017).

According to Jameton (1984), moral distress develops in a situation "when one knows the right thing to do, but institutional constraints make it nearly impossible to pursue the right course of action." (p. 6). While this is a widely cited description of moral distress, it has remained underproblematised, especially in empirical studies. This is evident in the mounting dissatisfaction with the existing conceptualisations (e.g. Hanna, 2004; McCarthy and Deady, 2008; Weinberg, 2009; Musto and Rodney, 2016).

In a review examining the delineation and deployment of moral distress, McCarthy and Gastmans (2015) highlight the multitude of different definitions in the nursing ethics literature, pointing out that most of these continue to draw on Jameton's description (e.g. Fantus et al., 2017; Lev and Ayalon, 2018). However, some scholars aspire a broader understanding of the phenomenon (e.g. Campbell et al., 2016; Fourie, 2015). Yet others, in turn, argue that the concept has already been over-extended and is at risk of becoming analytically meaningless (e.g. Wocial, 2016).

Hence, the most critical voices propose that we abandon the flawed construct and move on (Johnstone and Hutchinson 2015). Clearly, there is need for further conceptual analysis, as the insufficient conceptual clarity has led to various, disparate and sometimes even dubious ways of studying the phenomenon empirically (McCarthy and Gastmans, 2015; Repenshek, 2009).

This article aims to contribute to the clarification of the concept of moral distress by examining the ways in which it has been understood in the existing nursing and social work literature. More specifically, the objective is to identify the challenges and potential problems presented by the 
current definition(s) and operationalisation(s) of the concept. The article thus aspires to illuminate the complex and dynamic nature of the phenomenon and thereby help to facilitate better quality empirical research on moral distress in the social work context. In the following sections, the main features of the current conceptualisations are introduced and the potential challenges and problems they pose elaborated.

\section{The main components of moral distress}

A commonly shared feature of the existing conceptualisations of moral distress seems to be the presence of two interconnected elements. The first is related to the existence of some sort of event that is characterised by a person's awareness of having restricted moral agency, and the second to the psychological and physiological suffering, i.e. distress, this induces (Jameton 1984, Campbell et al., 2016, Morley et al., 2017). In the literature, these elements are defined in multiple ways and are variously emphasised (McCarthy and Gastmans, 2015; Campbell et al., 2016, Morley et al. 2017).

Owing to this dual nature, moral distress could be understood as 1) a psychological/ physiological response or 2) a phenomenon that leads to such a response (see Fourie, 2015, p. 93). Jameton (1984) himself seemed to see the phenomenon as both a response and a specific cause. Due to this interesting duality, Carina Fourie (2015) defines moral distress as a compound phenomenon (Fourie, 2015, p. 93). However, conceptualising these two main elements has been very difficult and has also led to insufficient attention being paid to the relationship between them. 


\section{Constrained moral agency}

The early descriptions given by Jameton $(1984 ; 1993)$ focused on restricted moral agency, and particularly on the role of institutional constraints (see Hanna 2004; Morley et al., 2017). In his original description, Jameton (1984) differentiated the experience of moral distress from the experiences of moral uncertainty and moral dilemmas. For social workers, situations involving moral decision-making that affects the lives of service users are an integral part of their everyday practice, and hence they are likely to frequently experience feelings of moral uncertainty. For example, they might feel unsure about the right course of action in the often highly complex and challenging situations, they encounter in their work. Professionals cannot always know the right thing to do: they might not have sufficient information to guide their moral decision-making and they cannot predict where their decisions will lead them (see Campbell et al., 2016). However, according to Jameton (1984), in the case of moral distress a person is sure about the right thing to do but is prevented from doing it. Thus, this feeling of certainty about the right course of action could be understood as a key element of moral distress.

This feeling of certainty could also differentiate the experience of moral distress from the response to an ethical dilemma (Jameton 1984; see also Hanna, 2004), another situation commonly encountered in social work practice. In the case of a dilemma, the social worker is forced to choose between two (or even more) courses of action in a situation in which neither of the conflicting obligations or ethical principles overrides the other (McConnell, 2014). This means that the practitioner faced with the dilemma will inevitably experience at least some degree of ethical failure, because whatever she chooses to do will entail the transgression of other ethical principle (McConnell, 2014). 
However, in the case of moral distress, we cannot really talk about an ethical dilemma per se, at least not according to Jameton (1984), because in a situation in which moral distress develops, the social worker knows what the morally appropriate action is, but she is prevented from taking it. I would prefer to rephrase this as follows: she judges something as the right thing to do (see e.g. Dudzinski, 2016 p. 321) and simultaneously perceives that she is not able to do it. I will justify these modifications later when elaborating on the role of constraints and moral agency. However, not all scholars agree with Jameton's conceptualisation. Some reject the idea that people experience moral distress only when constrained from practising according to their moral code (e.g. Campbell et al., 2016; Morley et. al. 2017). They argue that simply facing a moral uncertainty, moral dilemma or moral conflict can also lead to the experience of moral distress. For Campbell and his colleagues (2016), the crucial aspect is that the person perceives that she is involved in a situation that she considers "morally undesirable" (p. 5-6). Fourie (2015) also proposes that moral distress might be best understood as a specific kind of psychological response to a morally challenging situation and, in addition to moral constraints, includes the moral conflicts in her definition (p. 92).

This broader understanding of moral distress, supported, for example, by Campbell and his colleagues (2016), while alluring, also poses problems, as it tends to include virtually the whole gamut of experiences of feeling bad resulting from being placed in "morally undesirable" situations. This could dilute the analytical power of the concept (see Wocial, 2016) while making it rather difficult to study empirically (see also Hamric, 2012).

Even if moral uncertainty and moral dilemmas are likely to induce negative feelings and discomfort in practitioners, should all these negative states be described as experiences of moral distress per se? Whatever the answer, the idea that moral conflict and uncertainty are potential 
conditions of moral distress (see Fourie 2015; Morley et al., 2017) is worth analysing further. Faced with a moral dilemma in which two clear moral principles apply but support mutually inconsistent actions, a social worker might be obliged to prioritise one principle over the other. Thus, she might not, for example, be able to act in the moral interests of all the stakeholders (see Morley et al., 2017).

Thus, the lines between moral constraints, moral conflicts and moral dilemmas are not perhaps as simple and straightforward as Jameton's (1984) description indicates (see Fourie, 2015; McCarthy and Gastmans 2015; Morley et al., 2017). The existence of moral conflict and uncertainty when combined with a requirement to act could also be understood as a constraint on moral action. For example, the professional, in seeking to act in her client's best interest, might have to do so on the basis of a principle that violates another important principle, such as that of respecting the client's right to confidentiality (see Campbell et al., 2016).

\section{Distress}

The second component, distress, has also been problematic. Whereas Jameton (1984) focused on institutional constraints, Judith Wilkinson (1987/88), a nursing scholar, showed greater concern about psychological suffering (Morley et al., 2017). She further refined Jameton's description by stressing the element of moral distress, which she defined in her empirical study as "the psychological disequilibrium and negative feeling state experienced when a person makes a moral decision but does not follow through by performing the moral behavior indicated by that decision" (Wilkinson, 1987-1988, p. 16). According to Wilkinson (1987/88) moral distress produces strong, negative and interconnected feelings such as guilt, frustration and anger. 
However, it remains unclear what these negative feeling states and psychological disequilibrium refer to. No consensus exists on them and various definitions of this component have been proposed. For example, Campbell and his colleagues (2016) refer to "one or more negative selfdirected emotions or attitudes", such as guilt, shame and self-criticism, that arise when a professional perceives herself as involved in a "morally undesirable" situation (p. 6). This is rather a broad definition, as it embraces a large range of negative self-directed feelings and attitudes.

Dudzinski (2015) in turn uses the narrower notion of moral emotion to refer to this experience that, arising out of moral angst or conflict and involving a crisis of conscience, leads to a sense of powerlessness, frustration, confusion and guilt (p. 321). However, Johnstone and Hutchison (2015) point out that moral emotions such as guilt and regret may simply be manifestations of conscience rather than moral distress per se. The above-mentioned examples are just few of the many conceptualisations in circulation. This conceptual messiness has deservedly prompted McCarthy and Deady (2008) to question the psychological dimension by asking what moral distress at bottom is: is it a "range of emotions" or a "group of symptoms" (p. 259; see also Dudzinski, 2015)?

Hence, it is thus certainly worth asking how psychological and physiological negative responses, such as headaches and sleeplessness, (e.g. Wilkinson, 1987/88,) can be usefully conceptualised and operationalised (see also Fourie, 2015, p. 97) and, further, how severe and repetitive they are required to be for them to qualify as moral distress. Alternatively, it can be asked whether any sort of negative psychological or physiological response to a morally undesirable situation should be regarded as moral distress. This in turn prompts the question of what then separates moral distress from a moral injury, that is to say, long-lasting psychological harm caused by the 
actions of professionals themselves or of other people that violate the same professional's moral beliefs (Haight et al., 2016).

In other words, the element of distress remains nebulous, and thus its conceptualisation requires greater rigour. However, based on the empirical and theoretical studies on moral distress, it is reasonable to argue that neither component alone is sufficient to constitute the experience of moral distress (see also Wilkinson 1987/88). By this, I mean that a social worker can (and is quite likely to) feel distressed, if she is muddling through her day with insufficient time resources, but only experiences moral distress if she feels that she is obliged to compromise her ethical principles due lack of time (Mänttäri-van der Kuip, 2016). Thus, it might be useful to differentiate more general (di)stress from moral distress (Dudzinski, 2015; Fourie, 2015).

Naturally, it is also possible that a practitioner who feels unable to practice according to the moral code of her profession does not, for some reason, feel anguished by it. This may, for example, be due to lack of moral sensitivity (see Lützén and Kvist, 2012) or lack of moral responsibility (see Gorin, 2016). Thus, it is reasonable to argue that both elements of moral distress need to be present. Consequently, the suggestion by Morley and her colleagues (2017) that involvement in a morally challenging event and reacting to this situation with psychological distress are the necessary conditions for moral distress.

Stages and types of moral distress - dynamic reality versus static conceptualization

If the experience of moral distress is understood as consisting of the two elements elaborated above and thus a compound phenomenon as characterised by Fourie (2015), what is the relation 
between these elements? Based on the earlier empirical and theoretical research it is arguable that moral distress follows the inability to act (Morley et al., 2017; McCarthy and Gastmans, 2015). In other words, an ethical conflict or constraint prompts some sort of negative psychological or physiological response (Wilkinson 1987/88; see also Fourie 2015). Nevertheless, precisely how this happens remains unclear. This question appears to have been under-discussed yet is crucial with respect to the conceptualisation process. This brings us to the thus far incomplete discussion on the development and potential stages of moral distress.

In the early 1990s, Jameton continued his conceptualisation process by dividing moral distress into two stages (Jameton, 1993). The first stage, initial distress occurs when a practitioner is prevented from doing what she considers the right thing to do owing to institutional constraints, provoking, for example, feelings of frustration and anxiety (Jameton, 1993). A social worker might for example feel obliged to place a child in a residential home that she does not consider answers that child's needs. Her superior has considered the option proposed by the social worker too costly, leaving the social worker feeling that she will have to accept a less suitable option despite her fears that the child will not receive adequate support in that placement. This forced decision gives rise to feelings of distress manifested in such emotions as frustration and anger. According to Jameton (1993), the second stage of moral distress, i.e. reactive distress, follows when the worker is not able to act upon the initial distress and is a lingering state that impairs well-being over a longer period of time. This could mean that the social worker frequently finds herself in situations where she feels that her moral agency is compromised. For example, she sees her clients suffering because of the decisions that she feels she has been forced to make and experiences feelings of guilt and powerlessness. This reactive stage of moral distress has also been termed moral residue and is considered by some researchers as an outcome of unresolved 
moral distress and thus as a separate concept (Epstein and Hamric, 2009; Epstein and Delgado, 2010; Varcoe et al., 2012).

Thus, while the negative feeling state follows the constrained moral action or inaction, this process is not necessarily linear. Negative psychological responses can sometimes be delayed and manifest much later (Campbell et al., 2016). The kinds of events that involve constrained agency cannot always be clearly defined either. It is also possible that the development of moral distress does not follow the proposed two-staged model (see Campbell et al., 2016), which is potentially too static to capture the dynamic and evolving nature of the phenomenon. Thus, scholars who have been focusing on moral residue have proposed a crescendo effect model to capture the process by which the experience of moral distress develops into moral residue (Epstein and Hamric, 2009; Epstein and Delgado, 2010). This model seeks to overcome the limitations of the more linear stage models, but thus far lacks adequate empirical support.

Thus, owing to all the previously mentioned complexities, some scholars propose that moral distress might better be understood as a cluster or umbrella concept (e.g. Hanna 2004) while others have identified diverse forms of moral distress such as mild distress, distress by association and delayed distress (Campbell et al., 2016). These proposals, in turn, seem to combine stages and explanations of moral distress, which theoretically can also be considered somewhat problematic and challenging for future empirical studies (see McCarthy and Deady 2008).

\section{"The right thing to do"}

According to Jameton (1984, p. 6) moral distress develops in a situation when a person "knows the right thing to do" but cannot pursue that course of action, and this seems to be the core 
premise of the prevalent moral distress theory (Johnstone and Hutchinson 2015). These situations in which a person feels constrained in making moral decisions are relatively common and normal in the field of social and health care. However, knowing the right thing to do is not a simple matter.

Various ways of approaching this issue have been suggested (see Hanna, 2004). One is to approach it from the perspective of professional ethical principles. Social workers have specific professional ethical principles that they are expected to follow in their work. (IFSW, 2018). Thus, it can be assumed that, as holders of these principles, social workers may experience moral distress if they are unable practice in accordance with them. For example, whereas a social worker is expected to support her client in participating fully in society and promote the client's right to self-determination (IFSW, 2018), her employer might require the worker to focus solely on activating the client to job seek even if the client in question is not fit to work. Tensions of this kind, which are becoming increasingly common in the current socio-political context (see Dall 2018), can, by constraining a social worker's moral agency, lead to experiences of moral distress. However, it is likely that professionals differ in a way they interpret these principles and put them into practice (Shdaimah and McGarry, 2018). It is thus also plausible that they differ in the effects on their wellbeing of having to compromise these principles.

In addition, it is plausible that social workers experience moral distress if other principles and values, e.g. personal or organisational, that they hold become compromised. Thus, it should be acknowledged that although many studies, this one included, focus on moral distress in the work setting, a professional, like any human being with ethical principles, can also experience moral distress outside of working life (Jameton, 2013). However, if moral distress is analysed in the context of social work practice, it is reasonable to argue that a key aspect of the inability to 
follow one's moral code is that it has a negative effect on the wellbeing of service users. For example, Dudzinski (2016) underlines the direct relationship between the experience of moral distress and patient wellbeing. Seen thus, it is the potential suffering of the client that feeds into the negative moral emotions experienced by the practitioner (Dudzinski, 2016; see also Wilkinson, 1987/88). This suffering is also connected to the professional accountability of practitioners, as they can be held responsible for the ethics of their conduct (see Jameton, 1984). It seems obvious that the question related to the right thing to do is a highly complex one. In social work practice, multiple subjective, professional, organizational and societal principles, values and accountabilities are intertwined in a complex manner. It should also be pointed out that even when a social worker judges a course of action as the right thing to do in a specific context and feels sure about it, this does not mean that it is necessarily morally correct (see Dudzinski, 2016). Professionals' moral judgements can be also mistaken, misguided or even wrong (Johnstone and Hutchinson, 2015). Thus, it might be more reasonable to place the emphasis on the professional's judgement that she knows the right thing to do, rather than on the rightness or wrongness of her moral judgement, moral action or inaction.

I argue that this complexity is not evident in the empirical analyses of moral distress. In most such studies, the emphasis is not on professionals' judgements or perceptions. Instead, actions are categorised as ethical or unethical, regardless of the thoughts of the professional. However, professionals are likely to differ in their interpretations of ethical principles (Shdaimah and McGarry, 2018) and commitment to them. This observation leads us into the question of the constraints on moral action and the problem of the so-called root causes. 


\section{The constraints of ethical practice and the problem of root causes}

As mentioned earlier, Jameton's (1984) interest was in the institutional and organisational constraints on moral action. In other words, he described the concept of moral distress in terms of external barriers (Jameton, 1984). Thus, in the case of moral distress, a nurse knows the right thing to do but is prevented from doing it because "institutional structure and conflicts with other co-workers create obstacles" (Jameton, 1993, p. 524). This emphasis on institutional and organisational constraints is also explicitly present in most empirical studies (e.g. McCarthy and Deady, 2015; Lev and Aylon, 2016; Morley et al., 2017) even if Wilkinson (1987/1988) had already added internal constraints such as self-doubt and socialisation to the following of orders in her definition.

Both the widely used instruments developed by Corley and her colleagues (2001), the Moral Distress Scale (MDS) and the Moral Distress Scale-Revised (MDS-R), consist of items that are considered the so-called root causes of moral distress. Most of the moral problems referred to in these items, in which respondents are asked to assess the level of moral distress they induce on a 7-point scale, can be considered external in their nature. Such problems include e.g. working in conditions of unsafe and inadequate staffing levels, and the provision of better care for patients who can afford to pay (Corley et al., 2001, p. 254; see Hamric, 2012).

The moral distress questionnaire that has been developed to assess the frequency and intensity of moral distress among social workers (Lev and Ayalon, 2016; 2018) is also based on the idea of predefined morally loaded events that has arisen in the context of social work in long-term care facilities. As a compound instrument akin to the previously mentioned instruments, it consist of two scales: the first aims to assess the frequency of predefined moral phenomena as the authors 
term them (altogether 15 items), such as acting in contradiction to one's professional beliefs, and a feeling of being driven more by financial interests than by the interests of one's clients (Lev and Ayalon, 2016; 2018). The second aims to assess the existence and the intensity of distress as a response to these moral phenomena (Lev and Ayalon, 2016; 2018).

This prompts the interesting question of whether an instrument designed to measure moral distress should or should not include such predefined root causes. If moral distress is a compound phenomenon consisting of responses and specific causes, are the latter in fact root causes of moral distress or causes of the phenomenon of restricted moral agency and the psychological responses this evokes (see Fourie, 2015)?

If the root causes are understood in the first meaning, in other words as the specific and predetermined causes of moral distress (see Fourie, 2015), the phenomenon is being conceptualised from the relatively narrow perspective of readily defined constraints, leaving little space for subjective judgements and evaluations. Of course, while it is perfectly plausible that, in the current context of austerity, social workers experience work-related moral distress due to these specific predetermined causes, such as being forced to prioritise economic considerations over the best interests of clients, they may in reality differ in this respect (see Epstein and Delgado, 2010; Barlem and Ramos, 2015; Mänttäri-van der Kuip, 2017). To allow for this possibility that the factors causing moral distress can vary among social workers, a more subjective, relational and contextual approach to these constraints might be more fruitful (see Epstein and Delgado, 2010).

I argue, therefore, that it might be worth differentiating the phenomenon itself, i.e. the experience of moral distress, from its antecedents or predictors (i.e. root causes) if one wishes to study both 
the phenomenon itself and the factors related to it (see Hanna 2004; Fourie, 2015; Mänttäri-van der Kuip, 2017).

Only institutional and organisational constraints?

Not all scholars agree with Jameton (1984) on the overriding role of external constraints (e.g. Hanna, 2004). One might even claim that this emphasis on institutional constraints could distort the image of the phenomenon. Could moral distress be prevented or relieved by attending solely to its institutional antecedents? Are there no other kinds of obstacles hampering ethical practice?

It is evident that social workers are not fully autonomous actors when practising their profession in different organisational and institutional settings (Weinberg, 2009). Rather they are part of a complex and multilayered system of relationships that is affected, for example, by the employing organisation and its strategies and practices as well as broader socio-political structures, policies and laws (Weinberg, 2009; Mänttäri-van der Kuip, 2016). These contexts can constrain, as well as facilitate their professional practice, moral decision making included (Weinberg, 2009; Musto and Rodney, 2015). However, it is plausible that the moral agency of a social worker can be restricted for other reasons as well.

Hanna (2004) claims that the role of institutional constraints has been overemphasised. A professional might also be hindered from practising according to her professional values due to internal constraints. These obstacles could be related to insufficient education, knowledge and skills (Grady et al., 2008; Christen and Katsarov, 2016), or lack of (moral) courage (Wilkinson, 1987/88; Dudzinski, 2016). Antecedents like these could, at least in theory, contribute to experiences of moral distress. It is also arguable that the ability to recognise moral issues in daily practice, i.e., the existence of some sort of ethical awareness and sensitivity (Lützén and Kvist, 
2012; Christen and Katsarov, 2016), and moral competence (see Johnstone and Hutchinson, 2015), are important preconditions of moral distress.

For example, a social worker might experience moral distress if she is aware that although she does not have the requisite skills or necessary knowledge to perform a given task in an ethically appropriate way, she nevertheless feels obliged to act. She might also notice the existence of oppressive practices in her employing organisation yet fails to challenge them for fear of losing her job. Thus, she ends up experiencing moral distress, as she feels that she does not have sufficient moral courage to act in a way that she considers ethically appropriate.

Thus, internal constraints can also induce moral distress. Interaction between external and internal constraints is also possible (Varcoe et al., 2012). For example, Christen and Katsarov (2016) argue that certain external factors, such a lack of resources, could make professionals morally less sensitive. Moral insensitivity could even serve as a coping mechanism for tackling experiences of moral distress (see p. 20). According to Christen and Katsarov (2016) while an increase in moral sensitivity might temporarily increase the experience of moral distress, this distress could motivate professionals to change their behaviour or to challenge constraints that they find morally questionable. They also propose that professionals should be better equipped with the skills and competences required to deal with the ethical aspects of their everyday practice in a constructive manner (Christen and Katsarov, 2016, p. 21; see also Lynch and Forde, 2016).

However, the indicators of moral distress used in the empirical studies on the issue have tended to emphasise institutional and organisational constraints (e.g. Corley et al., 2001; Lev and Ayalon, 2016), and, as mentioned earlier, to view these constraints as root causes. This is problematic, as focusing exclusively on external obstacles to ethical action could limit our 
understanding of the phenomenon. Moreover, attributing moral distress solely to external obstacles runs the risk of ignoring the possibility of personal moral failure (Hanna, 2004). Similarly, the assumption that professionals experience moral distress when confronted with certain predefined obstacles, and that what is considered the right thing to do is defined by these obstacles, leaves little space for subjective evaluations, thereby potentially restricting their moral agency.

These considerations prompt the question, what does being constrained from pursuing what one believes to be the morally right course of action ultimately mean? Jameton (1984) seemed to be referring to real barriers to ethical practice; however, are we really forced to do what we perceive we are being forced to do? It is possible that some constraints are not 'real' but instead derive from fears and imperfect knowledge. A social worker might, for example, find out that her colleague has been making unjust decisions, and hence feels a moral responsibility to blow the whistle but she is afraid of the potential consequences. However, instead of being shunned by her work community and slandered because she has drawn attention to an injustice, her colleagues might be grateful to her for her moral action. Thus, a perceived but not in fact real obstacle may constrain a person's moral agency (Wilkinson, 1987/88).

\section{Towards broader, more subjective and relative conceptualisations?}

To conclude, the endeavour to conceptualise the complex experience of moral distress is challenging, and finding a satisfactory, comprehensive enough definition turns out to be rather difficult. The existing studies indicate that a slightly broader understanding of the notion of restricted moral agency is needed. Moral distress could be understood as a "response to morally 
challenging situations" (see Fourie 2015, p. 97) which seriously restricts a person's moral agency (Varcoe et al. 2012). However, this broader definition potentially dilutes the analytical power of the concept and is likely to complicate empirical research. The constraints on moral action could also be understood more broadly. Instead of being viewed exclusively as external, their internal sources (see McCarthy and Gastmans 2015) and the interaction between the two should also be acknowledged (Varcoe et al., 2012). It is also plausible that constraints on moral action are subjectively perceived (Wilkinson 1987/88) as well as objective and that the former might or might not have much to do with reality.

My central claim is that constraints on moral action should not be included in the definition or among the instruments of moral distress, even if this seems to be the prevailing practice in the empirical research (e.g. Lev and Ayalon, 2018). Instead, these root causes should be understood as antecedents of moral distress, not as components of it. As Varcoe and her colleagues (2012) propose, it might be fruitful to define moral distress as an individually experienced phenomenon, which is shaped by the person's individual characteristics and the various contexts in which the person is acting (p. 56). Thus, Varcoe and her colleagues (2012) support a broader and more relational understanding of the constraints on moral action. I argue that such a broader understanding of the constraints on moral action offers more options when trying to tackle the moral distress experienced by professionals in the field of social work. Over-emphasis on external constraints could steal professionals' moral agency and lead to their portrayal as victims of the system and incapable of action (Johnstone and Hutchinson, 2015). Similarly, seeing constraints on moral action as antecedents of moral distress makes it possible to identify and tackle them on the political and organisational levels, as well as in social work education (Grady et al., 2008; Lynch and Forde, 2016). 
Thus, I argue that the existing studies on moral distress have suffered from an oversimplified idea about the role of constraints on moral action. Research has indicated that the phenomenon is more complex and dynamic than Jameton's original description might suggest (Hanna, 2004). This is also applies to the relationship between structure and agency (Musto and Rodney, 2016). It might be useful to understand both structures and agents, in the present instance social workers, as open systems, as they can influence each other (Musto and Rodney, 2016; see also Varcoe et al., 2012). This is not to diminish the role of structures but to emphasise that structures alone do not have the power to determine how professionals act (see Weinberg, 2009).

At the level of practice, the goal should not be to ameliorate experiences of moral distress per se but rather to remove the obstacles to moral action and to enhance moral agency (see e.g. Varcoe et al., 2012; Fourie, 2016; Dudzinski 2016; Fourie, 2016; Gorin 2016; McFadden et al., 2018). As Lützén and Kvist (2012) argue, in addition to the well-known negative impacts, moral distress can have a positive impact on professionals and their clients (see also Wilkinson 1987/88) and might even operate as a positive catalyst (Lützén and Kvist, 2012) offering an opportunity for moral growth (Hanna, 2004). Thus, some level of moral distress may be necessary, as it indicates moral sensitivity to unethical actions (McCarthy and Gastmans, 2015; Christen and Katsarov, 2016; Fourie, 2016). The experience of moral distress might also lead professionals to oppose injustices and enable them to take moral actions such as resisting unethical requests or mandates (Shdaimah and McGarry, 2018, see also IFSW, 2018). This in turn may facilitate talk about moral stress rather than distress (see Lützén and Kvist, 2012), as the notion of distress tends to emphasise the negative effects of the phenomenon.

The ultimate question is whether we really need a concept burdened with so much fuzziness? Would it be better to abandon it, as Johnstone and Hutchinson (2015) propose? The concept of 
moral distress has resonated strongly among scholars and practitioners, which is understandable as it aims to understand and give a name to an experience commonly encountered by frontline workers (see Dudzinski, 2016). However, the descriptions and definitions currently applied tend to lack the clarity that is necessary for successful empirical study. It is important that this conceptual weakness is recognised in the field of social work research.

Thus, despite all the above-mentioned complexities, the concept of moral distress can serve as an important tool for understanding and analysing experiences of moral suffering in the frontline. However, before moving too eagerly to measure it, a more profound understanding of the phenomenon must be achieved (see McCarthy and Gastmans 2015). This could be pursued by focusing first on a proper qualitative examination of moral (di)stress in the context of social work, and then, only after successfully scrutinising and conceptualising it, moving towards designing an instrument to measure it. Furthermore, to demonstrate that the instrument measures what it is intended to measure, a proper validation process is necessary. Otherwise, the findings and hence the advancement of the moral distress theory in general are at risk (see Kim 2009). In other words, defining the experience in all its complexity and building a valid instrument to measure it continues to present researchers with a major, but fascinating challenge (McCarthy and Gastmans 2015), one that should also be addressed in social work research.

\section{Literature}

Mänttäri-van der Kuip, M. (2016) 'Moral Distress among Social Workers - The Role of Insufficient Resources', International Journal of Social Welfare, 25 (1), pp. 86-97.

Mänttäri-van der Kuip, M. (2017) 'The challenges of measuring moral distress in the context of social and health care', SAGE Research Methods Cases, SAGE Publications Ltd, doi: $10.4135 / 9781526406729$. 
Baines, D. and van den Broek, D. (2017) 'Coercive care: Control and coercion in the restructured care workplace', The British Journal of Social Work, 47 (1), pp. 125-142.

Barlem, E. L. and Ramos, F. R. (2015) 'Constructing a theoretical model of moral distress', Nursing ethics, 22 (5), pp. 608-615.

Baugerud, G. A., Vangbæk, S. and Melinder, A. (2018) 'Secondary Traumatic Stress, Burnout and Compassion Satisfaction among Norwegian Child Protection Workers: Protective and Risk Factors', British Journal of Social Work, 48 (1), pp. 215-235.

Campbell, S. M., Ulrich, C. M. and Grady, C. (2016) 'A broader understanding of moral distress', The American Journal of Bioethics, 16 (12), pp. 2-9.

Christen, M. and Katsarov, J. (2016) 'Moral sensitivity as a precondition of moral distress', The American Journal of Bioethics, 16 (12), pp. 19-21.

Conneely, E. and Garrett, P. M. (2015) 'Social workers and social justice during a period of intensive neoliberalization: A preliminary investigation from the Republic of Ireland', Journal of Progressive Human Services, 26 (2), pp. 126-147.

Corley, M. C., Elswick, R. K., Gorman, M. and Clor, T. (2001) 'Development and evaluation of a moral distress scale', Journal of advanced nursing, 33 (2), pp. 250-256.

Dall, T. (2018) 'Social work professionals' management of institutional and professional responsibilities at the micro-level of welfare-to-work', European Journal of Social Work, 113. Published online: 23 May 2018.

Dudzinski, D. M. (2016) 'Navigating moral distress using the moral distress map', Journal of medical ethics, 42 (5), pp. 321-324.

Epstein, E. G. and Hamric, A. B. (2009) 'Moral distress, moral residue, and the crescendo effect', The Journal of clinical ethics, 20 (4), pp. 330-342.

Epstein, E. G. and Delgado, S. (2010) 'Understanding and addressing moral distress', Online Journal of Issues in Nursing, 15 (3), manuscript 1, doi:10.3912/OJIN.Vol15No03Man01.

Fantus, S., Greenberg, R. A., Muskat, B. and Katz, D. (2017) 'Exploring moral distress for hospital social workers', British Journal of Social Work, 47 (8), pp. 2273-2290.

Fenton, J. (2014) 'An analysis of 'ethical stress' in criminal justice social work in Scotland: the place of values', The British Journal of Social Work, 45 (5), pp. 1415-1432.

Ferguson, I. and Lavalette, M. (2013) 'Crisis, austerity and the future (s) of social work in the UK', Critical and Radical Social Work, 1 (1), pp. 95-110.

Fourie, C. (2015) 'Moral distress and moral conflict in clinical ethics' Bioethics, 29 (2), pp. 9197. 
Fourie, C. (2016) 'The ethical significance of moral distress: inequality and nurses' constraintdistress', The American Journal of Bioethics, 16 (12), pp. 23-25.

Fronek, P. and Chester, P. (2016). 'Moral outrage: social workers in the Third Space', Ethics and Social Welfare, 10 (2), pp. 163-176.

Garrett, P. M. and Bertotti, T. F. (2017) 'Social work and the politics of 'austerity': Ireland and Italy', European Journal of Social Work, 20 (1), pp. 29-41.

Gorin, M. (2016) 'The role of responsibility in moral distress', The American Journal of Bioethics, 16 (12), pp. 10-11.

Grady, C., Danis, M., Soeken, K., O'Donnell, P., Taylor, C., Farrar, A. and Ulrich, C. (2008) 'Does ethics education influence the moral action of practicing nurses and social workers?', The American Journal of Bioethics, 8 (4), pp. 4-11.

Grootegoed, E. and Smith, M. (2018) 'The Emotional Labour of Austerity: How Social Workers Reflect and Work on Their Feelings towards Reducing Support to Needy Children and Families', The British Journal of Social Work Advance Access published January 10, 2018, doi:10.1093/bjsw/bcx151

Haight, W., Sugrue, E., Calhoun, M. and Black, J. (2016) 'A scoping study of moral injury: Identifying directions for social work research', Children and youth services review, 70, pp. 190-200.

Hamric, A. (2012) 'Empirical research on moral distress: Issues, challenges, and opportunities', HEC Forum: An Interdisciplinary Journal on Hospitals' Ethical and Legal Issues, 24 (1), pp. 39-49.

Hanna, D. R. (2004) 'Moral distress: The state of art', Research and Theory for Nursing Practice: An International Journal, 18 (1), pp. 73-93.

IFSW (2018) Global Social Work Statement of Ethical Principles. Retrieved from https://www.ifsw.org/global-social-work-statement-of-ethical-principles/.

Jameton, A. (1984) Nursing practice: The ethical issues, London, Prentice-Hall.

Jameton, A. (1993) 'Dilemmas of moral distress: Moral responsibility and nursing practice'. AWHONNS Clinical Issues in Perinatal \& Women's Health Nursing, 4 (4), pp. 542-551.

Jameton, A. (2013) 'A reflection on moral distress in nursing together with a current application of the concept', Bioethical Inquiry, 10 (3), pp. 297-308.

Johnstone, M. J. and Hutchinson, A. (2015) ' Moral distress'-time to abandon a flawed nursing construct?', Nursing ethics, 22 (1), pp. 5-14.

Kim, H., Ji, J. and Kao, D. (2011) 'Burnout and physical health among social workers: A threeyear longitudinal study', Social work, 56 (3), pp. 258-268 
Kim, Y. M. (2009) 'Validation of psychometric research instruments: The case of information science'. Journal of the American Society for Information Science and Technology, 60 (6), $1178-1191$.

Lev, S. and Ayalon, L. (2016) 'Moral distress among long-term care social workers: questionnaire validation', Research on Social Work Practice Advance Access published Ocotober 5, 2016, doi:10.1177/1049731516672070.

Lev, S. and Ayalon, L. (2018) 'Moral distress among long-term care social workers: questionnaire validation', Research on Social Work Practice Advance Access published January 11, 2018, doi:10.1080/00981389.2017.1414096.

Lützén, K. and Kvist, B. E. (2012) 'Moral distress: a comparative analysis of theoretical understandings and inter-related concepts', HEC forum, 24 (1), pp. 13-25.

Lynch, D. and Forde, C. (2016) 'Moral distress' and the beginning practitioner: preparing social work students for ethical and moral challenges in contemporary contexts', Ethics and Social Welfare, 10 (2), pp. 94-107.

McCarthy, J. and Deady, R. (2008) 'Moral distress reconsidered', Nursing Ethics, 15 (2), pp. 254-262.

McCarthy, J. and Gastmans, C. (2015) 'Moral distress: A review of the argument-based nursing ethics literature', Nursing Ethics, 22 (1), pp. 131-152.

McConnell, T. (2014) 'Moral dilemmas', in Zalta, E. N. (ed), The Stanford Encyclopedia of Philosophy (Fall 2014 Edition). Stanford, Metaphysics Research Lab, Center for the Study of Language and Information, Stanford University. Retrieved from http://plato.stanford.edu/archives/fall2014/entries/moral-dilemmas/.

McFadden, P., Mallett, J., Campbell, A. and Taylor, B. (2018). 'Explaining Self-Reported Resilience in Child-Protection Social Work: The Role of Organisational Factors, Demographic Information and Job Characteristics', The British Journal of Social Work, Advance Access published April, 9, 2018, doi: 10.1093/bjsw/bcy015.

Morley, G., Ives, J., Bradbury-Jones, C. and Irvine, F. (2017) 'What is 'moral distress'? A narrative synthesis of the literature', Nursing ethics Advance Access published October 8, 2017, doi:10.1177/0969733017724354.

Musto, L. C. and Rodney, P. A. (2016) 'Moving from conceptual ambiguity to knowledgeable action: using a critical realist approach to studying moral distress', Nursing Philosophy, 17 (2), pp. 75-87.

Ravalier, J. M. (2018) 'Psycho-Social Working Conditions and Stress in UK Social Workers', The British Journal of Social Work Advance Access published April 26, 2018, doi:10.1093/bjsw/bcy023 
Repenshek, M. (2009) 'Moral distress: inability to act or discomfort with moral subjectivity?', Nursing Ethics, 16 (6), pp. 734-742.

Shdaimah, C. S. and McGarry, B. (2018), 'Social workers' use of moral entrepreneurship to enact professional ethics in the field: case studies from the social justice profession', The British Journal of Social Work, 48 (1), pp. 21-36.

Sunderland, N., Catalano, T., Kendall, E., McAuliffe, D. and Chenoweth, L. (2010) 'Exploring the concept of moral distress with community-based researchers: An Australian study'. Journal of Social Service Research, 37(1), pp. 73-85.

Ulrich, C., O’Donnell, P., Taylor, C., Farrar, A., Danis, M. and Grady, C. (2007) 'Ethical climate, ethics stress, and the job satisfaction of nurses and social workers in the United States', Social science \& medicine, 65 (8), pp. 1708-1719.

Varcoe, C., Pauly, B., Webster, G. and Storch, J. (2012) 'Moral distress: Tensions as springboards for action', HEC forum, 24, (1), pp. 51-62.

Weinberg, M. (2009) 'Moral distress: A missing but relevant concept for ethics in social work', Canadian Social Work Review, 26 (2), pp. 139-151.

Welbourne, P. (2011) 'Twenty-first century social work: the influence of political context on public service provision in social work education and service delivery', European Journal of Social Work, 14 (3), pp. 403-420.

Wilkinson, J. M. (1987/1988) 'Moral distress in nursing practice: Experiences and effects', Nursing Forum, 23 (1), pp. 16-29.

Wocial, L. D. (2016) 'A misunderstanding of moral distress', The American Journal of Bioethics, 16 (12), pp. 21-23. 